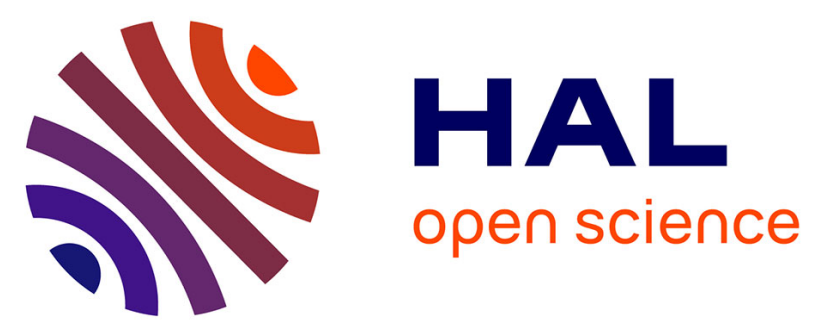

\title{
Sequential double second-order nonlinear optical switch by an acido-triggered photochromic cyclometallated platinum(ii) complex.
}

Julien Boixel, Véronique Guerchais, Hubert Le Bozec, Agisilaos Chantzis, Denis Jacquemin, Alessia Colombo, Claudia Dragonetti, Daniele Marinotto, Dominique Roberto

\section{To cite this version:}

Julien Boixel, Véronique Guerchais, Hubert Le Bozec, Agisilaos Chantzis, Denis Jacquemin, et al.. Sequential double second-order nonlinear optical switch by an acido-triggered photochromic cyclometallated platinum(ii) complex.. Chemical Communications, 2015, 51 (37), pp.7805-7808. 10.1039/C5CC01893E . hal-01141732

\section{HAL Id: hal-01141732}

\section{https://hal-univ-rennes1.archives-ouvertes.fr/hal-01141732}

Submitted on 16 Sep 2015

HAL is a multi-disciplinary open access archive for the deposit and dissemination of scientific research documents, whether they are published or not. The documents may come from teaching and research institutions in France or abroad, or from public or private research centers.
L'archive ouverte pluridisciplinaire HAL, est destinée au dépôt et à la diffusion de documents scientifiques de niveau recherche, publiés ou non, émanant des établissements d'enseignement et de recherche français ou étrangers, des laboratoires publics ou privés. 


\title{
Sequential double second-order nonlinear optical switch by an acido- triggered photochromic cyclometallated platinum(II) complex
}

\author{
Julien Boixel, ${ }^{a}$ Véronique Guerchais, ${ }^{\text {a* }}$ Hubert Le Bozec, ${ }^{a}$ Agisilaos Chantzis, ${ }^{\text {b }}$ Denis Jacquemin,, ,c* \\ Alessia Colombo, ${ }^{\mathrm{d}^{*}}$ Claudia Dragonetti, ${ }^{\mathrm{d}, \mathrm{e}}$ Daniele Marinotto, ${ }^{\mathrm{e}}$ and Dominique Roberto ${ }^{\mathrm{d}, \mathrm{e}}$
}

An unprecedented DTE-based Pt(II) complex, 2(o), stands as the first example of a sequential double nonlinear optical switch, induced first by protonation and next upon irradiation with UV light.

Among compounds with second-order nonlinear optical (NLO) properties, ${ }^{1}$ those with commutable NLO responses are of growing importance due to their potential for novel applications in emerging photonic technologies. ${ }^{2}$ For this reason, there is great interest in finding efficient ways to switch the second-order NLO activity at the molecular level. Recently, considerable efforts have been made in designing and preparing coordination complexes with effective redox- ${ }^{2,3}$ or photo- ${ }^{2,4}$ switchable second-order NLO response. For example, by using the photochromic DiThienylEthene (DTE) unit, ${ }^{5}$ some of us demonstrated the photo-modulation of the NLO response in several DTE-based bipyridine metal complexes. ${ }^{6}$ The ability to switch the NLO response of cyclometallated $\mathrm{Pt}(\mathrm{II})$ complexes is appealing, and a density functional theory (DFT) investigation showed that it can be achieved by using well designed DTE ligands. ${ }^{7}$ Recently some of us found that the excellent photochromic properties of an open-DTE-based Pt(II) complex (1(o) in Chart 1) allow the photo-induced switching of its second-order NLO properties, ${ }^{8}$

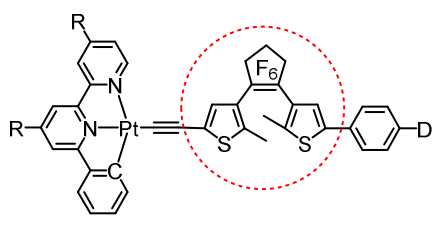

1(o)

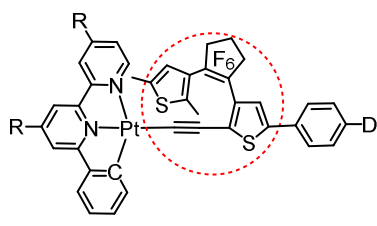

2(o) as measured by the Electric-Field-Induced Second Harmonic generation EFISH technique, ${ }^{9}$ due to ring closure of the DTE unit and concomitant formation of an extended $\pi$-conjugated ligand $(\mathbf{1}(\mathbf{c}))$.

Chart 1 Chemical structures of DTE-based $\left(\mathrm{N}^{\wedge} \mathrm{N}^{\wedge} \mathrm{C}\right) \mathrm{Pt}(\mathrm{II})$ complexes $\mathbf{1}$, $\left(\mathrm{R}={ }^{\mathrm{n}} \mathrm{Hex}, \mathrm{D}=\mathrm{NMe}_{2}\right)$ and $\mathbf{2}\left(\mathrm{R}={ }^{\mathrm{t}} \mathrm{Bu}, \mathrm{D}=\mathrm{NBu}_{2}\right)$

We have designed and synthesised a new type of DTE-based platinum complex 2(o) (Chart 1) where the organometallic fragment, and the dialkylaminophenyl group are located on the same thiophene ring of the photochromic DTE unit (rather than at both ends of the DTE unit as in $\mathbf{1}(\mathbf{o})$ ), the cyclometalated $\mathrm{Pt}(\mathrm{II})$ acetylide moiety being bounded to one of the reactive carbon atoms. ${ }^{10,11}$ This design gives rise to an extended $\pi$-conjugated alkynyl ligand in the open form, accompanied with metal-to-ligand/ligand-to-ligand charge transfer (MLCT/LLCT) transitions. On the contrary, the formation of a tetrahedral centre at the $C_{2}$ carbon in 2(c) induces a new conjugated pathway centered on the DTE. Moreover, the introduction of a strong donating dialkylamino end group, allows to dramatically modify the electronic structure by protonation. Here, we present an unexpected sequential double modulation of the NLO properties of metal complexes.

Scheme 1 A three-state system: complex 2(o) and the protonated open$\mathbf{2} \mathbf{H}^{+}(\mathbf{o})$ and closed-ring isomers $2 \mathbf{H}^{+}(\mathbf{c})$. i) $\mathrm{HBF}_{4}-\mathrm{OEt}_{2}, \mathrm{CH}_{2} \mathrm{Cl}_{2}$; ii) $\mathrm{CH}_{2} \mathrm{Cl}_{2}$, hv (350 nm); iii) $\mathrm{CH}_{2} \mathrm{Cl}_{2}$, hv (580 nm).

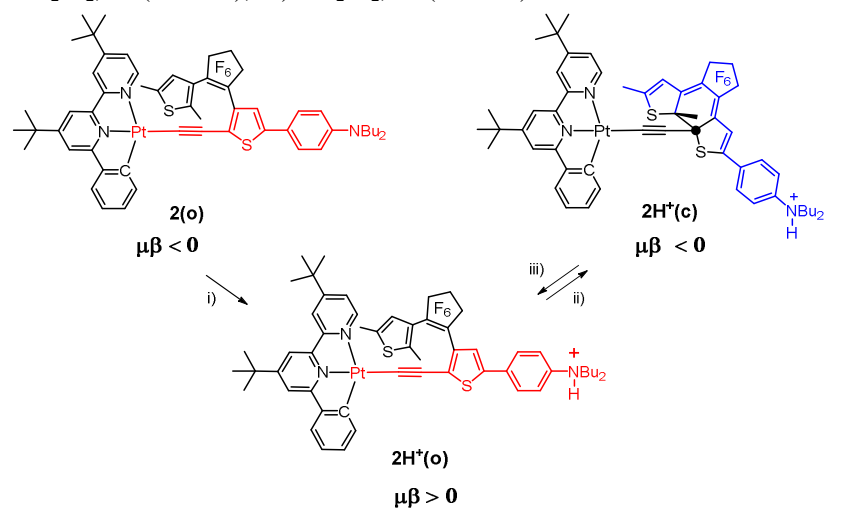

Complex 2 was synthesised by a standard procedure starting from $\left(\mathrm{N}^{\wedge} \mathrm{N}^{\wedge} \mathrm{C}\right) \mathrm{Pt}-\mathrm{Cl}$ and the appropriate DTE-based alkyne (Scheme $\mathrm{S} 1, \mathrm{ESI} \dagger){ }^{8}$ The DTE-based ligand was prepared following a multi-step procedure. The two different thiophene derivatives were successively connected to the perfluorocyclopentene.

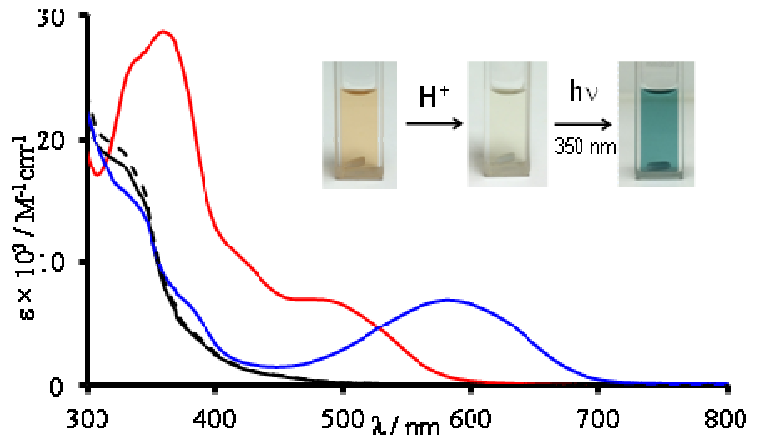

Fig. 1 Absorption spectral changes in $\mathrm{CH}_{2} \mathrm{Cl}_{2}$ at $298 \mathrm{~K}$ of complex 2(o) (red line), upon addition of $\mathrm{HB}_{4}-\mathrm{OEt}_{2}$ (black line), after irradiation at 350 $\mathrm{nm}$ (blue line) and after irradiation at $580 \mathrm{~nm}$ (dashed black line).

The UV-vis absorption spectrum $\left(\mathrm{CH}_{2} \mathrm{Cl}_{2}\right)$ of $\mathbf{2}(\mathbf{o})$ is shown in Fig. 1 whereas the spectroscopic data are summarized in Tables 1 and S1 (ESI $\dagger$ ). Complex 2(o) exhibits characteristic absorption bands for cyclometalated platinum(II) complexes, ${ }^{12}$ i.e., intraligand (IL) $\pi-\pi^{*}$ transitions of the DTE-based alkynyl and cyclometalated $\mathrm{N}^{\wedge} \mathrm{N}^{\wedge} \mathrm{C}$ ligands in the region of 300-370 $\mathrm{nm}$ and MLCT $\mathrm{d} \pi(\mathrm{Pt}) \rightarrow \pi^{*}\left(\mathrm{~N}^{\wedge} \mathrm{N}^{\wedge} \mathrm{C}\right)$ mixed with some LLCT $\pi(\mathrm{C} \equiv \mathrm{C}-) \rightarrow \pi^{*}\left(\mathrm{~N}^{\wedge} \mathrm{N}^{\wedge} \mathrm{C}\right)$ transitions in the visible region. The spectrum of $2(\mathbf{o})$ extends up to $600 \mathrm{~nm}$, as a result of the presence of an extended $\pi$-conjugated alkynyl ligand. 
To further rationalize the absorption spectra, Time-Dependent DFT (TD-DFT) calculations have been carried out (see ESI $\dagger$ for computational details), using the $\mathrm{PBE} 0^{13}$ hybrid functional and the Polarizable Continuum Model $^{14}$ (PCM) to account for solvent effects. The computed transition wavelengths are listed in Table 1 whereas Fig. 2 gives the Natural Transition Orbitals $^{15}$ (NTO) describing the $\mathrm{S}_{0} \rightarrow \mathrm{S}_{1}$ transition for the different species. The $S_{0} \rightarrow S_{1}$ transition in 2(o) (computed at $573 \mathrm{~nm}$ ) involves predominantly interligand charge transfer (LLCT) from the amino-DTE-acetylide ligand to the $\mathrm{N}^{\wedge} \mathrm{N}^{\wedge} \mathrm{C}$ part coordinated to the Pt, with some metal-to-ligand (MLCT) charge transfer character. Moreover, theory predicts that the high-energy part of the spectrum of $\mathbf{2 ( 0 )}$ is dominated by transitions located on the ligands around the $\mathrm{Pt}$ atom (intraligand, IL) in agreement with expectations (see ESI $\dagger$ ).

Table 1. Experimental and computed absorption wavelengths $\left(\mathrm{CH}_{2} \mathrm{Cl}_{2}\right)$. Theoretical calculations at the PCM-PBE0 level. The data between parenthesis are the oscillator strengths.

\begin{tabular}{lcc}
\hline & $\lambda^{\text {Exp }}[\mathrm{nm}]$ & $\lambda^{\text {Theo }}[\mathrm{nm}](f)$ \\
\hline $\mathbf{2 ( 0 )}$ & $362,423,483$ & $327(0.17), 372(1.06)$, \\
& & $465(0.13), 573(0.29)$ \\
$\mathbf{2 H}^{+}(\mathbf{o})$ & 332,440 & $367(0.36), 369(0.23)$, \\
& & $410(0.21), 485(0.38)$ \\
$\mathbf{2 H}^{+}(\mathbf{c})$ & $343,380,585$ & $325(0.23), 358(0.14)$, \\
& & $452(0.10), 613(0.30)$ \\
\hline
\end{tabular}

Interestingly, complex 2(o) did not show any photoreactivity by irradiation with light at $350 \mathrm{~nm}$ in $\mathrm{CH}_{2} \mathrm{Cl}_{2}$ or cyclohexane solution. It was previously advocated that a possible resonant cumulenic-quinoid form 2(o) (see Scheme S3 in ESI) would be responsible of the inhibition of the photocyclization reaction, ${ }^{10 \mathrm{a}}$ but DFT calculations based on Natural Bond Orbital ${ }^{16}$ (NBO) atomic charges and on inspection of the bond lengths in the optimized geometry indicate that $\mathbf{2 ( 0 )}$ has no significant contribution from this quinoid structure (see ESI $\dagger$ ). The photochromic reactivity of the DTE moiety can be restored by protonation. Quaternization of the nitrogen atom of the dibutylamino end group was achieved by in situ addition of tetrafluoroboric acid $\left(\mathrm{HBF}_{4}-\mathrm{OEt}_{2}\right)$ into a $\mathrm{CH}_{2} \mathrm{Cl}_{2}$ solution of $\mathbf{2 ( \mathbf { o } )}$ (Scheme 1). The absorption spectrum of the protonated complex $\mathbf{2} \mathbf{H}^{+}(\mathbf{o})$ is blue-shifted over the whole electronic spectrum in comparison with 2(o) (Fig. 1), as the result of the suppression of the strong electron-donating character of the dibutylamino end group. ${ }^{17}$ This analysis is supported by TD-DFT: the $S_{0} \rightarrow S_{1}$ transition (computed at $485 \mathrm{~nm}$ ) now involves CT from the DTEacetylide moiety to the $\mathrm{N}^{\wedge} \mathrm{N}^{\wedge} \mathrm{C}$ part with practical no participation of the amino group (Fig. 2). TD-DFT qualitatively restores the experimentally observed blue-shift of the $S_{0} \rightarrow S_{1}$ band when protonation of $\mathbf{2}(\mathbf{0})$ takes place $(88 \mathrm{~nm}$ instead of 151 $\mathrm{nm})$. Upon irradiation at $350 \mathrm{~nm}$, the colourless solution of $2 \mathbf{H}^{+}(\mathbf{o})$ turned blue due to the formation of the closed-ring isomer $2 \mathbf{H}^{+}(\mathbf{c})$, as indicated by the typical absorption band at $585 \mathrm{~nm}$ (Fig. 1). Irradiation with visible light $(580 \mathrm{~nm})$ quantitatively recovered the initial spectrum of the open-ring isomer $2 \mathbf{H}^{+}(\mathbf{o})$ (Fig. 1). In the case of $\mathbf{2} \mathbf{H}^{+}(\mathbf{c})$, the $\mathrm{S}_{0} \rightarrow \mathrm{S}_{1}$ transition (computed at $613 \mathrm{~nm}$ ) is mostly an IL state centered on the DTE according to TD-DFT. This observation is of particular interest because it shows that, when an organometallic moiety is linked to a DTE unit at the reactive carbon, the lowest excited-state does not conserve a CT nature after ring-closure of the DTE.

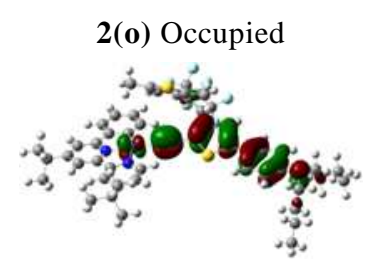

$\mathbf{2 H}^{+}(\mathbf{o})$ Occupied
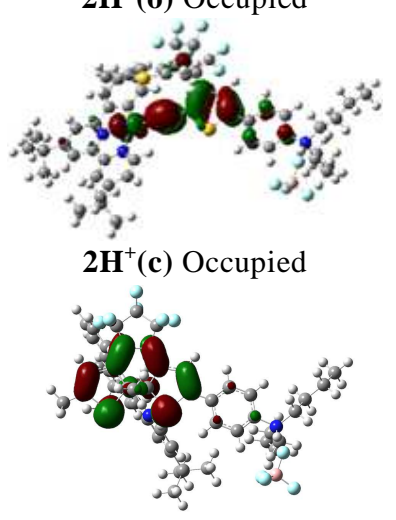

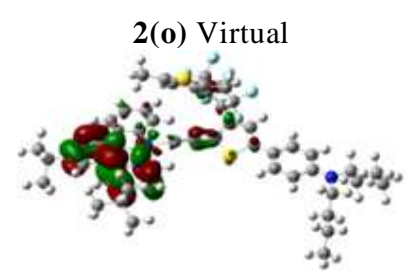

$2 \mathbf{H}^{+}(\mathbf{o})$ Virtual

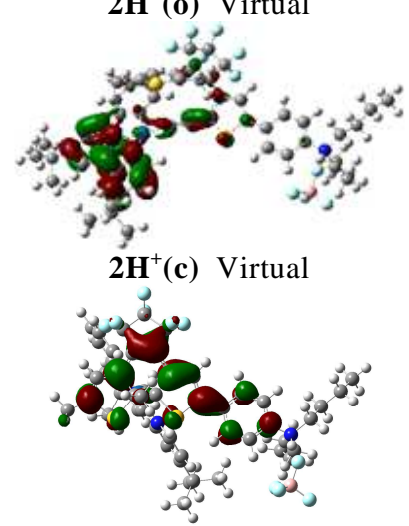

Fig. 2 NTO pairs corresponding to the $\mathrm{S}_{0} \rightarrow \mathrm{S}_{1}$ electronic transition of systems $\mathbf{2}(\mathbf{o}), \mathbf{2} \mathbf{H}^{+}(\mathbf{o})$ and $2 \mathbf{H}^{+}(\mathbf{c})$ calculated with PBE0 functional (0.03 isovalue used).

The second-order NLO response of $\mathbf{2}(\mathbf{o}), \mathbf{2} \mathbf{H}^{+}(\mathbf{o})$ and $\mathbf{2} \mathbf{H}^{+}(\mathbf{c})$ were determined by the EFISH method working in $\mathrm{CH}_{2} \mathrm{Cl}_{2}$ at a concentration of $10^{-3} \mathrm{M}$ with a non-resonant incident wavelength of $1.907 \mu \mathrm{m}$ (see ESI $\dagger$ ). ${ }^{9}$ Although it was traditionally used to study neutral molecules, the EFISH technique can be applied for the determination of the second-order NLO response of ionic species by working in a solvent of low dielectric constant which favours ion-pairing. ${ }^{18} \mathrm{We}$ found that $\mathbf{2 ( 0 )}$ is characterized by a large value of $\mu \beta_{\text {EFISH }}\left(-496 \times 10^{-48}\right.$ esu, see Table 2$)$. The NLO response doesn't change upon irradiation in agreement with the lack of photochromism of complex $2(\mathbf{o})$.

Protonation of this complex in situ with $\mathrm{HBF}_{4}-\mathrm{OEt}_{2}$ gives $\mathbf{2} \mathbf{H}^{\mathbf{+}}(\mathbf{o})$ that also has a large value of $\mu \beta_{\mathrm{EFISH}}\left(690 \times 10^{-48} \mathrm{esu}\right)$ but with inversion of the sign of the quadratic hyperpolarizability. Further irradiation at $350 \mathrm{~nm}(5 \mathrm{~min})$ leads to ring closure, and to a high value of $\mu \beta_{\text {EFISH }}\left(-925 \times 10^{-48}\right.$ esu) with again, a negative quadratic hyperpolarizability (see Table 2 ).

The nonlinear optical properties of $\mathbf{2 ( o )}, \mathbf{2} \mathbf{H}^{+}(\mathbf{o})$ and $\mathbf{2} \mathbf{H}^{+}(\mathbf{c})$ have been also calculated using the $\omega \mathrm{B} 97 \mathrm{X}-\mathrm{D}^{19}$ long-range corrected functional (see ESI $\dagger$ ).

Theoretical and experimental results are compared in Table 2. It turns out that the dipole moment decreases upon protonation of 2(o) whereas it increases on going from $2 \mathbf{H}^{+}(\mathbf{o})$ to $\mathbf{2} \mathbf{H}^{+}(\mathbf{c})$. Theory predicts that all three systems have $\mu \beta$ values of the same order of magnitude in agreement with the experimental findings (Table 2). Moreover, the NLO switching ability is confirmed by theory with both $\mathbf{2 ( o )}$ and $\mathbf{2} \mathbf{H}^{+}(\mathbf{c})$ systems having a negative quadratic hyperpolarizability contrarily to $\mathbf{2 H}^{+}$(o) (Table 2). 
Table 2. Dipole moments and quadratic hyperpolarizabilities calculated using the $\omega \mathrm{B} 97 \mathrm{X}-\mathrm{D}$ functional compared to the experimental measurements.

\begin{tabular}{lcccc}
\hline & $\begin{array}{c}\mu^{\text {Theo }} \\
\left(10^{-18} \text { esu }\right)\end{array}$ & $\begin{array}{c}\beta^{\text {Theo }} \\
\left(10^{-30} \text { esu }\right)\end{array}$ & $\begin{array}{c}\mu \beta^{\text {Theo }} \\
\left(10^{-48} \text { esu }\right)\end{array}$ & $\begin{array}{c}\mu \beta^{\text {Exp }} \\
\left(10^{-48} \text { esu }\right)\end{array}$ \\
\hline $\mathbf{2 ( o )}$ & 19.6 & -83.4 & -1635 & -496 \\
$\mathbf{2 H}^{+}(\mathbf{o})$ & 13.4 & 77.2 & 1034 & 690 \\
$\mathbf{2 H}^{+}(\mathbf{c})$ & 23.4 & -47.6 & -1114 & $-925^{\mathrm{a}}$ \\
\hline
\end{tabular}

${ }^{\mathrm{a}}$ after irradiation at $350 \mathrm{~nm}$ for 5 minutes

In conclusion, the novel DTE-based platinum(II) system presented here is of particular interest, being, to our knowledge, the first example of an in situ sequential double nonlinear optical switch where the NLO response is modulated first by protonation and then upon irradiation with UV light. One key point in the system is that the sign of the $\mu \beta$ response changes at each step.

This work was supported by European Research Council (Marches Grant 278845), the Région des Pays de la Loire (recrutement sur poste stratégique), MIUR (FIRB 2003: RBNE033KMA and FIRB 2004: RBPR05JH2P) and CNR.

$\dagger$ Electronic supplementary information (ESI) available: Synthetic procedures, spectral characterization, EFISH measurements and computational details.

\section{Notes and references}

${ }^{a}$ UMR 6226 CNRS-Université de Rennes 1, Institut des Sciences Chimiques de Rennes, Campus de Beaulieu, 35042 Rennes, France. Email: veronique.guerchais@univ-rennes1.fr;

${ }^{b}$ UMR CNRS 6230, Université de Nantes, CEISAM, 44322 Nantes cedex

3, France.E-mail: denis.jacquemin@univ-nantes.fr;

${ }^{c}$ Institut Universitaire de France, IUF, 103, Blvd St Michel, F-75005

Paris cedex 5, France;

${ }^{d}$ Dipartimento di Chimica dell'Università degli Studi di Milano, UdR dell'INSTM, 20133 Milano, Italy.E-mail: alessia.colombo@unimi.it; ${ }^{e}$ ISTM-CNR, 20133 Milano, Italy.

1 J. Zyss Molecular Nonlinear Optics: Materials, Physics and Devices. Academic Press, Boston, 1994.

2 For example: (a) G. Berkovic, V. Krongauz and V. Weiss, Chem. Rev., 2000, 100, 1741; (b) I. Asselberghs, K. Clays, A. Persoons, M. D. Ward and J. McCleverty, J. Mater. Chem., 2004, 14, 2831; (c) D. Marinotto, R. Castagna, S. Righetto, C. Dragonetti, A. Colombo, C. Bertarelli, M. Garbugli and G. Guglielmo, J. Phys. Chem. C, 2011, 115, 20425; (d) B. J. Coe, in Non-Linear Optical Properties of Matter, M. G. Papadopoulos, A. J. Sadlej, J. Leszczynski, Eds., Springer Verlag: Berlin, 2006, 571; (e) F. Castet, V. Rodriguez, J. L. Pozzo, L. Ducasse, A. Plaquet and B. Champagne, Acc. Chem. Res., 2013, 46, 2656.

3 For example: (a) B.J. Coe, S. Houbrechts, I. Asselberghs and A. Persoons, Angew. Chem. Int. Ed., 1999, 38, 366; (b) M. Malaun, Z. R. Reeves, R. L. Paul, J. C. Jeffery, J. McCleverty, M. D. Ward, I. Asselberghs, K. Clays and A. Persoons, Chem. Commun., 2001, 49; (c) F. Paul, K. Costuas, I. Ledoux, S. Deveau, J. Zyss, J.-F. Halet and C. Lapinte, Organometallics, 2002, 21, 5229; (d) D. Espa, L. Pilia, L. Marchiò, M. L. Mercuri, A. Serpe, A. Barsella, A. Fort, S. J. Dalgleish, N. Robertson and P. Deplano, Inorg. Chem., 2011, 50, 2058.

4 (a) V. Guerchais, L. Ordronneau and H. Le Bozec, Coord. Chem. Rev., 2010, 254, 2533; (b) K. A. Green, M. P. Cifuentes, M. Samoc, M. G. Humphrey, Coord. Chem. Rev., 2011, 255, 2530; (c) B. J. Coe, Coord. Chem. Rev., 2013, 257, 1438.

5 (a) M. Irie, Chem. Rev., 2000, 100, 1685; (b) M. Irie, T. Fukaminato, K. Matsuda and S. Kobatake, Chem. Rev., 2014, 114, 12174.

6 (a) V. Aubert, V. Guerchais, E. Ishow, K. Hoang-Thi, I. Ledoux, K. Nakatani and H. Le Bozec, Angew. Chem. Int. Ed., 2008, 47, 577; (b) L. Ordronneau, V. Aubert, R. Métivier, E. Ishow, J. Boixel, K. Nakatani, F. Ibersiene, D. Hammoutène, A. Boucekkine, H. Le Bozec and V. Guerchais, Phys. Chem. Chem. Phys., 2012, 14, 2599; (c) H. Nitadori, L. Ordronneau, J. Boixel, D. Jacquemin, A. Boucekkine, A.
Singh, M. Akita, I. Ledoux, V. Guerchais and H. Le Bozec, Chem. Commun., 2012, 48, 10395; (d) L. Ordronneau, H. Nitadori, I. Ledoux, A. Singh, J. A. G. Williams; M. Akita, V. Guerchais and H. Le Bozec, Inorg. Chem., 2012, 51, 5627; (e) L. Ordronneau, V. Aubert, V. Guerchais, A. Boucekkine, H. Le Bozec, A. Singh, I. Ledoux and D. Jacquemin, Chem. Eur. J., 2013, 19, 5845.

7 M.-Y. Zhang, C.-H. Wang, W.-Y. Wang, N.-N. Ma, S.-L. Sun and Y.Q. Qiu, J. Phys. Chem. A, 2013, 117, 12497.

8 J. Boixel, V. Guerchais, H. Le Bozec, D. Jacquemin, A. Amar, A. Boucekkine, A. Colombo, C. Dragonetti, D. Marinotto, D. Roberto, S. Righetto and R. De Angelis, J. Am. Chem. Soc., 2014, 136, 5367.

9 (a) B.F. Levine and C.G. Bethea, J. Chem. Phys., 1975, 63, 2666; (b) I. Ledoux and J. Zyss, Chem. Phys., 1982, 73, 203.

10 For examples of switching units, in which the $\pi$-conjugated chain is extended from 2- and 5-positions in one thienyl unit of the DTE, see: (a) N. Tanifuji, M. Irie and K. Matsuda, J. Am. Chem. Soc., 2005, 127, 13344; (b) K. Yumoto, M. Irie and K. Matsuda, Org. Lett., 2008, 10, 2051; (c) J. Cai, A. Farhat, P. B. Tsitovitch, V. Bodani, R. D. Toogood and R. S. Murphy, J. Photochem. Photobiol. A, 2010, 212, 176; (d) T. Fukaminato, T. Hirose, T. Doi, M. Hazama, K. Matsuda and M. Irie, J. Am. Chem. Soc., 2014, 136, 17145.

11 A similar design was reported by some of us for DTE-based bipyridines, see: (a) V. Aubert, E. Ishow, F. Ibersiene, A. Boucekkine, J. A. G. Williams, L. Toupet, R. Metivier, K. Nakatani, V. Guerchais and H. Le Bozec, New J. Chem., 2009, 33, 1320; (b) L. Ordronneau, J. Boixel, V. Aubert, M. S. Vidal, S. Moya, P. Aguirre, L. Toupet, J. A. G. Williams, H. Le Bozec and V. Guerchais, Org. Biomol. Chem., 2014, 12, 979.

12 W. Lu, B.-X. Mi, M. C. W. Chan, Z. Hui, C.-M. Che, N. Zhu and S.-T. Lee, J. Am. Chem. Soc., 2004, 126, 4958.

13 C. Adamo and V. Barone, J. Chem. Phys., 1999, 110, 6158.

14 J. Tomasi, B. Mennucci and R. Cammi, Chem. Rev., 2005, 105, 2999. 15 R.L. Martin, J. Chem. Phys., 2003, 118, 4775.

16 J. P. Foster and F. Weinhold, J. Am. Chem. Soc., 1980, 102, 7211.

17 (a) F. Guo and W. Sun, Inorg. Chem., 2005, 44, 4055; (b) G. S. M. Tong, Y.-C. Law, S. C. F. Kui, N. Zhu, K. H. Leung, D. L. Phillips and C.-M. Che, Chem. Eur. J., 2010, 16, 6540.

18 (a) V. Alain, M. Blanchard-Desce, I. Ledoux-Rak and J. Zyss, Chem. Comm., 2000, 353; (b) F. Tessore, D. Roberto, R. Ugo, P. Mussini, S. Quici, I. Ledoux-Rak and J. Zyss, Angew. Chem. Intern. Ed., 2003, 42, 456; (c) A. Valore, E. Cariati, C. Dragonetti, S. Righetto, D. Roberto, R Ugo, F. De Angelis, S. Fantacci, A. Sgamellotti, A. Macchioni and D. Zuccaccia, Chem. Eur. J., 2010, 16, 4814; (d) F. Tessore, E. Cariati, F. Cariati, D. Roberto, R. Ugo, P. Mussini, C. Zuccaccia and A. Macchioni, ChemPhysChem, 2010, 11, 495.

19 J. -D. Chai and M. Head-Gordon, Phys. Chem. Chem. Phys., 2008, 10, 6615 . 


\section{Graphical Abstract}

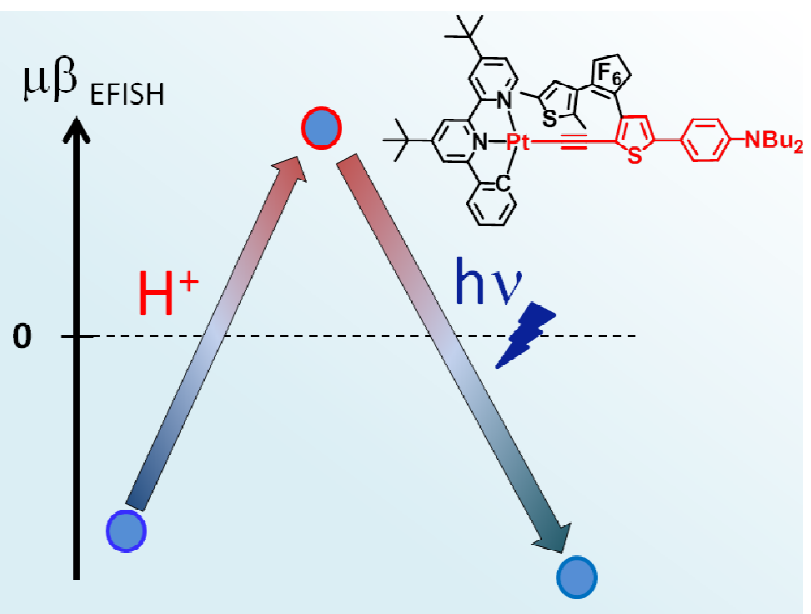

